\title{
Envelhecimento humano e desenvolvimento da doença periodontal
}

\author{
Human aging and periodontal disease development
}

\author{
Envejecimiento humano y desarrollo de la enfermedad periodontal
}

\author{
Evandro Franco da Rocha ${ }^{1 *}$, Amanda Beltrame Seibel ${ }^{1}$, Amanda Natália Nogueira ${ }^{1}$, Valéria \\ Campanelli Franco da Rocha ${ }^{1}$.
}

\section{RESUMO}

Objetivo: Analisar através da literatura especializada as alterações que ocorrem no periodonto decorrentes do processo de envelhecimento. Métodos: Revisão narrativa através da análise da literatura publicada em artigos de periódicos. Resultados: Com o avanço da idade, diversas alterações celulares ocorrem no corpo humano: diminuição da resposta inflamatória e retardo na regeneração e cicatrização dos tecidos. No periodonto, ocorre a diminuição do número de fibras do ligamento periodontal, diminuição da vascularização e da capacidade de cicatrização do osso alveolar. A imunosenescência também possui um papel importante no desenvolvimento da doença periodontal. Idosos com periodontite apresentam aumento de mediadores próinflamatórios e neutrófilos. Apesar da quantidade de células inflamatórias ser semelhante em jovens e idosos a resposta inflamatória destes últimos ocorre de maneira deficiente, podendo deixá-los mais susceptíveis à doença periodontal. Entretanto isto pode não ser determinante para o desenvolvimento da doença, pois, sendo a periodontite resultado da exposição prolongada ao longo da vida a periodontopatógenos. Considerações finais: $O$ envelhecimento celular pode não ser a causa para o desenvolvimento da doença periodontal. A soma de múltiplos fatores como a exposição prolongada ao biofilme, associação a doenças sistêmicas, comprometimento motor e imunológico, exposição a substâncias químicas como álcool e tabaco podem contribuir.

Palavras-chave: Periodontite, Envelhecimento, Periodonto.

\begin{abstract}
Objective: Analyze through the literature the changes that occur in the periodontium due to the aging process. Methods: Narrative review through the analysis of published literature in journal articles. Results: With the advancement of age, several cellular changes occur in the human body: decreased inflammatory response and delayed regeneration and tissue healing. In the periodontium, there is a decrease in the number of fibers of the periodontal ligament, a decrease in vascularization and in the healing capacity of the alveolar bone. Aging also plays an important role in the development of periodontal disease. Elderly patients with periodontitis present increased pro-inflammatory mediators and neutrophils. Although the amount of inflammatory cells is similar in young and old the inflammatory response of the latter occurs poorly, which may make them more susceptible to periodontal disease. However, this may not be determinant for the development of the disease, since periodontitis is the result of prolonged exposure to periodontal disease. Final considerations: Cell aging may not be the cause for the development of periodontal disease. The sum of multiple factors such as prolonged exposure to biofilm, association with systemic diseases, motor and immune compromise, exposure to chemical substances such as alcohol and tobacco may contribute.
\end{abstract}

Key words: Periodontitis, Aging, Periodontium.

${ }^{1}$ Universidade Regional de Blumenau (FURB), Blumenau SC. *E-mail: evandrovaleria@gmail.com 


\section{RESUMEN}

Objetivo: Analizar a través de la literatura las alteraciones periodontales derivadas del envejecimiento. Métodos: Revisión narrativa de la literatura publicada en artículos de periódicos. Resultados: Con el envejecimiento, alteraciones celulares ocurren en el cuerpo humano: disminución de la respuesta inflamatoria y retardo en la regeneración y cicatrización. En el periodonto, la disminución del número de fibras del ligamento periodontal, de la vascularización y de la capacidad de cicatrización del hueso. El envejecimiento tiene un papel importante en el desarrollo de la periodontitis ya que presentan un aumento de mediadores inflamatorios y neutrófilos. Aunque la cantidad de células inflamatorias es similar en jóvenes y ancianos, la respuesta inflamatoria de estos últimos ocurre de manera deficiente, pudiendo dejarlos más susceptibles a la periodontitis. Sin embargo esto puede no ser determinante para el desarrollo de la enfermedad, pues, siendo la periodontitis resultante de la exposición prolongada a lo largo de la vida a patógenos periodontales. Consideraciones finales: El envejecimiento celular puede no ser la causa para el desarrollo de la periodontitis. Múltiples factores como la exposición prolongada al biopeliculas, la asociación a enfermedades sistémicas, el compromiso motor e inmunológico, la exposición a sustancias químicas como el alcohol y el tabaco pueden contribuir.

Palabras clave: Periodontitis, Envejecimiento, Periodonto.

\section{INTRODUÇÃO}

Tem-se como definição que a doença periodontal é uma enfermidade inflamatória que ocorre no periodonto, tendo como principal fator etiológico a placa bacteriana, sendo uma progressão da gengivite não tratada, que tem como consequência a destruição do cemento, ligamento periodontal e osso alveolar, causando perda de inserção e podendo resultar na perda do dente (NOVAK MJ e NOVAK KF, 2011).

A doença periodontal tem afligido as populações desde os primórdios, tendo histórico em antigas civilizações, começando a ser realmente estudada por volta de 1800 . Porém, há cinco décadas, ainda se acreditava que a doença era inevitável, progressiva e culminava com a perda dental. Hoje, sabe-se que a doença tem tratamento e pode ser modificada por diversos fatores sistêmicos e fatores extrínsecos ao organismo (OFFENBACHER S et al., 2008).

Entre 1990 e 2010, a doença periodontal foi classificada como a sexta mais prevalente no mundo, aumentando com o avanço da faixa etária. Na América Latina, atinge uma grande parte da população, difere na proporção quanto à condição socioeconômica, e é maior a partir da quarta década de vida. No Brasil, como no resto do mundo é mais incidente na faixa etária acima dos 60 anos (ARAUJO MG e KUKEKAVA F 2007; GOMES et al., 2010; FECHINI BRA e TROMPIERE N, 2012; KASSEBAUM NJ et al., 2014).

No panorama mundial atual, tem ocorrido uma mudança na pirâmide etária da população. Tem diminuído o número de crianças e aumentado a quantidade de idosos. Essa mudança tem como principal consequência a elevação da expectativa de vida, proporcionada, entre outros fatores, pelo melhor acesso aos serviços de saúde (KANSO S, 2015).

Além do crescimento da população de idosos, estes estão conservando seus dentes por mais tempo, e as diversas alterações que ocorrem no organismo com o envelhecimento tornam-se relevantes e determinantes de diversas patologias sistêmicas que podem afetar a saúde bucal. Também se manifestam alterações celulares que podem ser consideradas fatores de risco para a ocorrência e desenvolvimento da periodontite, associadas a fatores modificadores externos. Um idoso com doença periodontal pode sofrer prejuízos em sua nutrição, dificultando o seu desempenho em atividades normais do dia a dia, diminuindo drasticamente sua qualidade de vida (ACEVEDO RA et al., 2001, GOMES SGF et al., 2010; FECHINI BRA e TROMPIERE N, 2012). 
Diante disso, o objetivo deste trabalho foi analisar as mudanças que ocorrem no periodonto decorrentes do processo de envelhecimento humano, e se estas podem ser um fator de risco para a incidência da doença periodontal.

\section{REVISÃO BIBLIOGRÁFICA}

Existem fatores chamados predisponentes que atuam modificando o fator etiológico principal, no caso o biofilme microbiano, e alteram o curso da doença periodontal. Um destes fatores predisponentes é o comprometimento da imunidade celular, observada no sistema imune do idoso, associada à condição de má nutrição que muitas vezes o acompanha (ACEVEDO RA et al., 2001).

Entretanto em pesquisas, animais idosos tiveram uma maior imunidade adaptativa contra periodontopatógenos, mas a sua resposta inflamatória apresentou-se reduzida, o que poderia aumentar a susceptibilidade à periodontite e levando a uma maior ausência de dentes. Ebersole JL et al. (2016) avaliaram mudanças na expressão de inflamação de alguns genes relacionados ao envelhecimento durante a saúde e a periodontite. A expressão de genes relacionados à inflamação, não mudou com a idade em tecidos gengivais saudáveis, porém notaram-se mudanças na expressão gênica quando a mucosa foi constantemente exposta a bactérias, alterando a resposta imune, associada ao envelhecimento, levando à infecção persistente e inflamação crônica. Por fim a perda precoce dos dentes causou um aumento significativo no nível circulante de corticosterona, supressão dos osteoblastos para a formação óssea e a ativação dos osteoclastos induzindo reabsorção óssea, o que prejudica a homeostase dinâmica da formação e reabsorção óssea, levando à redução da força óssea com o avançar da idade (KURAHASHI M et al., 2015; WU Y et al.,2016).

Trabalhando com metabolismo ósseo, Lossrdorfer S et al., (2010) compararam parâmetros de diferenciação, resposta celular e fatores locais envolvidos na regulação do metabolismo ósseo alveolar em células do ligamento periodontal, em pacientes de diferentes idades, e observaram que, com o avanço desta, ocorre uma diminuição dos genes marcadores de osteoblastos, e a exposição ao hormônio paratireoideano (PTH) indicou uma queda considerável na produção de ostecalcina. Portanto, as células do ligamento periodontal de indivíduos mais velhos apresentam um fenótipo menos diferenciado e uma resposta reduzida ao PTH, o que sugere uma habilidade comprometida para a manutenção do equilíbrio do tecido e uma limitação na capacidade de reparo com o avanço da idade.

Os pacientes idosos apresentam também alterações nos tecidos bucais como ligamento periodontal, que apresenta diminuição na vascularização, na atividade mitótica e no número de fibras; mudanças no osso alveolar, que pode apresentar diminuição da vascularização e capacidade de cicatrização, e no cemento, que aumenta de espessura conforme o avanço da idade (ACEVEDO RA et al. 2001), porém o contato direto da cavidade oral com o ambiente externo e os fatores de risco, tornam difícil distinguir entre os efeitos causados por fatores ambientais e os efeitos do envelhecimento intrínseco.

Embora a doença periodontal esteja associada ao tempo, e o próprio envelhecimento parece ser responsável pela doença, a mesma é influenciada por múltiplos fatores que foram encontrados associados à prevalência e incidência da doença periodontal (HUTTNER AE et al. 2009). Huttner AE et al. (2009) indicaram também em seu estudo uma redução das taxas de proliferação e quimiotaxia das células do tecido periodontal, como um evento intrínseco ao envelhecimento podendo influenciar o equilíbrio da saúde periodontal. Também o aumento da responsividade das células do ligamento periodontal ao estímulo bacteriano (LPS) e o estresse mecânico, poderiam resultar na liberação de citocinas pró-inflamatórias, responsáveis pela perda óssea exacerbada em idosos.

Por outro lado, Hebling E (2012) não encontrou alterações funcionais nas células do tecido periodontal durante o processo de envelhecimento embora existam alterações anatômicas e funcionais. Os efeitos do envelhecimento sobre os tecidos periodontais e as alterações biomoleculares das células do periodonto poderiam exacerbar a perda óssea em idosos com periodontite, efeitos estes possivelmente associados a alterações na diferenciação e proliferação de osteoblastos e osteoclastos; aumento da resposta das células 
periodontais à microbiota oral e tensão mecânica levando à secreção de citocinas envolvidas na perda óssea; e alterações sistêmicas endócrinas em idosos.

Oliveira MB et al. (2012) forneceram um estudo sintetizado sobre a influência da placa dental sobre a saúde bucal de idosos de 80 anos ou mais. E concluíram que idosos apresentam elevados índices de placa e cálculo; apresentam também aumento do índice CPOD, com predominância de dentes perdidos, em concordância com o estudo de López R et al. (2017) que relacionaram envelhecimento, doença periodontal e cáries e a vulnerabilidade dos idosos a essas doenças, concluindo que ainda existe uma grande quantidade dessas doenças para esse grupo.

Os maus hábitos de higiene dos idosos leva a um alto índice de doença periodontal que resulta em prejuízos para a saúde oral e sistêmica e somados a todos estes fatores, existe uma degradação do periodonto, ocasionando uma grande quantidade de raízes expostas aumentando a incidência de cáries radiculares nesses pacientes (REAL ISC et al. , 2011).

Öztürk VO et al. (2016) realizaram estudos para investigar os níveis do gene que está ligado à resposta inflamatória mediante uma bactéria (TREM-1) no fluido do sulco gengival crevicular e os níveis de periodontopatógenos no biofilme dental de uma população idosa. Os resultados permitiram aos autores concluírem que a gravidade da periodontite em idade avançada poderia ser simplesmente resultado do efeito inflamatório cumulativo da exposição prolongada à microrganismos, e não diretamente à quantidade de genes ligada à resposta inflamatória.

Os mediadores inflamatórios foram também estudados por Preshaw et al. (2017) que demostraram que a produção de mediadores pró-inflamatórios e neutrófilos, em pessoas com periodontite, aumentam em indivíduos mais velhos quando comparados aos mais jovens. Não está claro como o mecanismo imunológico muda com o avançar da idade para aumentar a suscetibilidade dos indivíduos à estas doenças.

O aumento da quantidade de idosos nos últimos anos é incontestável, bem como a maior expectativa de vida da população. Estes idosos, estão mantendo seus dentes por mais tempo em boca, o que resulta no aumento da incidência da doença periodontal. Quanto à incidência, os homens são os mais acometidos pela enfermidade, e, foram encontrados índices em que cerca de $60 \%$ dos idosos acima de 70 anos possuíam bolsas periodontais acima de $6 \mathrm{~mm}$, e $70 \%$ deles não tinham metade dos seus dentes presentes, mesmo afirmando que não possuíam nenhum problema bucal (OGAWA H et al., 2002; QUEIROZ CM et al., 2008; LÓPEZ $\mathrm{R}$ et al., 2017).

Há várias hipóteses para explicar o aumento da prevalência de doença periodontal em idosos. Dentre elas estão as alterações celulares e teciduais que ocorrem com o passar da idade, os hábitos de higiene que estas pessoas tiveram ao longo da vida e a imunosenescência, que sugere uma desregulação do sistema imunológico devido ao envelhecimento. O elevado índice de doença periodontal em indivíduos senis tem repercussão na saúde oral e sistêmica podendo levar a perdas dentárias, halitose, dificuldade de mastigação, subnutrição e risco de disseminação de bactérias por via venosa. É inegável a relação entre as condições sistêmicas dos idosos e sua saúde periodontal, sendo influenciadas diretamente por seus hábitos e o consumo frequente de álcool e tabaco (ACEVEDO RA et al., 2001; REAL ISC et al., 2011; DARBY I, 2015; LÓPEZ R et al., 2017).

Quanto às alterações celulares em tecidos e sistemas do corpo humano, pode-se destacar no sistema cardiovascular, respiratório, musculoesquelético e na resposta imunológica. Certas alterações também ocorrem na cavidade bucal, como a diminuição da regeneração tecidual e do número de fibras do ligamento periodontal e a redução da quimiotaxia das células. Também o aumento da responsividade das células do ligamento periodontal ao estímulo bacteriano (LPS) e o estresse mecânico, somadas à deficiência na vascularização e na capacidade de cicatrização do osso alveolar, são fatores responsáveis pela perda óssea exacerbada em idosos. Fatores genéticos também devem ser avaliados, como o encurtamento dos telômeros, que participa da replicação do DNA na multiplicação das células, porém, sofre um encurtamento a cada divisão, podendo causar função prejudicada em fibroblastos, células ósseas, células epiteliais e leucócitos, 
além de resultar em menos células-tronco funcionais (FECHINI BRA e TROMPIERE N, 2012; OLIVEIRA MB et al., 2012; JÖNSSON D, 2013).

A imunosenescência pode ter um papel importante no desenvolvimento da periodontite. Pessoas idosas com doença periodontal apresentam aumento de mediadores pró-inflamatórios e neutrófilos. Embora a quantidade de células inflamatórias seja semelhante em jovens e idosos a resposta inflamatória destes últimos ocorre de maneira deficiente, podendo deixá-los mais susceptíveis à doença periodontal. A supressão de osteoblastos e produção de osteoclastos associada à dificuldade de regeneração e alterações hormonais, como, por exemplo, o hormônio paratireoideano, nos idosos, gera uma exacerbação da perda óssea e, consequentemente, perda dental. Portanto, estas alterações imunológicas poderiam prejudicar a relação simbiótica entre bactérias orais e o hospedeiro levando à infecção persistente e inflamação crônica (ACEVEDO RA et al., LOSSRDORFER S et al.,2001; KURAHASHI M et al., 2015; WU $Y$ et al., 2016; EBERSOLE JL et al., 2016; PRESHAW PM et al., 2017, EBERSOLE J.L. et al., 2018).

Em contrapartida, alguns autores defendem a hipótese de que não há alterações funcionais nas células do tecido periodontal, e o envelhecimento unicamente não causa a periodontite nem influencia no desenvolvimento desta, então, a periodontite poderia resultar simplesmente da exposição prolongada a periodontopatógenos ao longo da vida, onde, fatores como doenças sistêmicas, medicamentos e fatores retentivos de biofilme precisam estar interligados para ocorrer à doença. Todavia, sabe-se que o envelhecimento causa alterações biomoleculares que podem acelerar a perda óssea em uma periodontite pré-existente. Idosos com doença periodontal, associada a alterações sistêmicas como diabetes, cardiopatias, nefropatias, apresentam maior risco de mortalidade se comparados à pacientes saudáveis (REAL ISC et al., 2011; HEBLING E, 2012; CHEN Y et al., 2015; ÖZTÜRK VO et al., 2016).

Divergindo desta hipótese, alguns estudos recentes envolvendo animais e alta tecnologia mostraram uma relação direta entre a doença periodontal e a idade, e encontraram associação de alterações genéticas relacionados a interleucinas com a severidade da doença periodontal. Porém, indicam que o envelhecimento celular isoladamente não é a causa para o desenvolvimento da periodontite, e sim, a soma de múltiplos fatores como exposição prolongada à placa bacteriana associada a doenças sistêmicas, fatores retentivos de biofilme, comprometimento da capacidade motora, substâncias químicas como álcool e tabaco e o comprometimento imunológico (REAL ISC et al., 2011; NAKAMA DM et al., 2012; FERNANDES-COSTA AN et al., 2013; DARBY I, 2015; EBERSOLE JL et al., 2016; RUKMINI J.N., et al. 2018).

Existe um aumento na incidência da doença periodontal em indivíduos idosos que pode ser correlacionada a alguns fatores, como a exposição prolongada a periodonto patógenos, o comprometimento da capacidade motora, que pode dificultar a remoção mecânica do biofilme, ou mesmo, medicamentos e fatores modificadores externos e substâncias químicas como álcool e cigarro. A senescência, que leva ao comprometimento do sistema imunológico, diminuição da capacidade de regeneração celular e alterações fisiológicas e morfológicas na cavidade bucal, necessita de mais estudos com enfoque nestas alterações a nível celular, para que se possa comprovar uma correlação direta destas com o desenvolvimento da doença periodontal.

\section{CONSIDERAÇÕES FINAIS}

Embora não se possa comprovar uma relação direta entre o envelhecimento e o surgimento da periodontite, algumas alterações sistêmicas e teciduais, fatores retentivos de biofilme e limitações da capacidade motora dos idosos, podem levar ao agravamento desta. Torna-se imprescindível um desenvolvimento metodológico que contemple as diversas variáveis envolvidas. Porém um dos fatores que pode ter limitado as pesquisas sobre o assunto é a tecnologia atualmente insuficiente para a realização destas, ou a busca de hipóteses incorretas pelos pesquisadores, impossibilitando que se estabeleça com exatidão esta correlação.

REAS/EJCH | Vol. Sup.26 | e775 | DOI: https://doi.org/10.25248/reas.e775.2019 Página 5 de $\mathbf{6}$ 


\section{REFERÊNCIAS}

1. ACEVEDO RA et al. Tratamento periodontal no paciente idoso. Revista da Faculdade de Odontologia de Passo Fundo,2001; 6(2):57-62.

2. ARAUJO MG, KUKEKAVA F. Epidemiologia da doença periodontal na América Latina. Revista de Periodontia, 2007; $17(2): 7-13$.

3. CHEN Y et al. Periodontal Disease and Risks of Kidney Function Decline and Mortality in Older People: A Community-Based Cohort Study. American Journal Kidney Disease, 2015; 66(2):223-230.

4. DARBY I. Periodontal considerations in older individuals. Australian Dental Journal, 2015; 60(1):14-19.

5. EBERSOLE JL, et al. Age and Periodontal Health - Immunological View. Current Oral Health Reports, 2018; 5(4):229-241.

6. EBERSOLE JL, et al. Effects of aging in the expression of NOD-like receptors and inflammasome-related genes in oral mucosa. Molecular Oral Microbiology, 2016; 31(1):18-32.

7. FECHINE BRA, TROMPIERI N. O processo de envelhecimento: as principais alterações que acontecem com o idoso com o passar dos anos. Revista Científica Internacional, 2012; 20(7):106-132.

8. FERNANDES CAN, et al. As Principais Modificações Orais que ocorrem durante o Envelhecimento. Revista Brasileira de Ciências da Saúde, 2013; 17(3):293-300.

9. GOMES SGF, et al. Aging and the periodontium. Brazilian Journal of Oral Sciences, 2010, 9(1):1-6.

10. HEBLING E. Effects of Human Ageing on Periodontal Tissues. Periodontals diseases - A clinician's Guide, In Tech, 2012. p. 343356.

11. HUTTNER AE et al. Effects of human aging on periodontal tissues. Special Care in Dentistry, 2009; 29(4):149-155.

12. JÖNSSON D. Tissue senescence and periodontal disease - A reciprocal association? Arquives of oral biology, 2013; 58(7):753754.

13. KANSO S. Processo de envelhecimento populacional - um panorama mundial. VI Workshop de Análise Ergonômica do Trabalho; III Encontro Mineiro de Estudos em Ergonomia; VIII Simpósio do Programa Tutorial em Economia Doméstica. Belo Horizonte; 2013.

14. KASSEBAUM NJ. Global Burden of Severe Periodontitis in 1990-2010: A Systematic Review and Metaregression. Journal of Dentistry Research, 2014, 93(11):1045-1053.

15. KURAHASHI M et al. Tooth Loss Early in Life Accelerates Age-Related Bone Deterioration in Mice. The Tohoku Journal of Experimental Medicine, 2015; 235(1):29-37.

16. LÓPEZ R et al. Ageing, dental caries and periodontal diseases. Journal of Clinical Periodontology, 2017; 44 (Suppl. 18): S145S152.

17. LOSSDÖRFER S et al. Aging affects the phenotypic characteristics of human periodontal ligament cells and the cellular response to hormonal stimulation in vitro. Journal of Periodontal Research, 2010; 45(6):764-771.

18. NAKAMA DM et al. Polimorfismo no gene IL-10 (-627) em idosos portadores de doença periodontal. Com Scientiae Saúde, 2012; 11(3):369-376.

19. NOVAK MJ, NOVAK KF. Periodontite Crônica. In: NEWMAN, M.G.; TAKEI, H.H.; KLOKKEVOLD, P.R.; CARRANZA, F.A. (Editores). Carranza: Periodontia clínica. Rio de Janeiro: Elservier, 2011, p. 164-168.

20. OFFENBACHER $S$ et al. Rethinking periodontal inflammation. Journal of Periodontology, 2008; 79(8):1577-1584.

21. OGAWA H et al. Risk factors for periodontal disease progression among elderly people. Journal of Clinical Periodontology, 2002; 29:592-597.

22. OLIVEIRA MB et al. Influência da placa dental sobre a saúde bucal de idosos de 80 anos ou mais. Revista de Pesquisa em Saúde, 2012; 13(1):53-56.

23. ÖZTÜRK VO. Impact of aging on TREM-1 responses in the periodontium: a cross-sectional study in an elderly population. BMC Infectious Diseases, 2016; 16(1):429.

24. PRESHAW PM et al. Age-related changes in immune function (immune senescence) in caries and periodontal diseases: a systematic review. Journal of Clinical Periodontology, 2017; 44(18):153-177.

25. QUEIROZ CM et al. Avaliação da condição periodontal no idoso. Revista Brasileira de Cirurgia de Cabeça e pescoço, 2008; 3:156159.

26. RAMOS LR et al. Envelhecimento populacional: uma realidade brasileira. Revista de Saúde Pública, 1987; 21(3):211-224.

27. REAL ISC et al. As doenças orais nos idosos - Considerações Gerais. Revista Portuguesa de Estomatologia Medicina Dentaria e Cirurgia Maxilofacial, 2011; 52(3):175-180.

28. RUKMINI JN, et al. Effect of Menopause on Saliva and Dental Health. Journal of International Society of Preventive and Community Dentistry, 2018; 8(6):529-533, 2018

29. WU Y. et al. Effect of Aging on Periodontal Inflammation, Microbial Colonization, and Disease Susceptibility. Journal of Dental Research, 2016; 95(4):460-466. 